\title{
Subacute oral toxicity investigation of selenium nanoparticles and selenite in rats
}

Hadrup, Niels; Löschner, Katrin; Mandrup Egebjerg, Karen; Ravn-Haren, Gitte; Frandsen, Henrik Lauritz; Larsen, Erik Huusfeldt; Lam, Henrik R.; Mortensen, Alicja

Published in:

Drug and Chemical Toxicology

Link to article, DOI:

$10.1080 / 01480545.2018 .1491589$

Publication date:

2019

Document Version

Peer reviewed version

Link back to DTU Orbit

Citation (APA):

Hadrup, N., Löschner, K., Mandrup Egebjerg, K., Ravn-Haren, G., Frandsen, H. L., Larsen, E. H., Lam, H. R., \& Mortensen, A. (2019). Subacute oral toxicity investigation of selenium nanoparticles and selenite in rats. Drug and Chemical Toxicology, 42(1), 76-83. https://doi.org/10.1080/01480545.2018.1491589

\section{General rights}

Copyright and moral rights for the publications made accessible in the public portal are retained by the authors and/or other copyright owners and it is a condition of accessing publications that users recognise and abide by the legal requirements associated with these rights.

- Users may download and print one copy of any publication from the public portal for the purpose of private study or research.

- You may not further distribute the material or use it for any profit-making activity or commercial gain

- You may freely distribute the URL identifying the publication in the public portal 


\section{Subacute Oral Toxicity Investigation of Selenium Nanoparticles and Selenite in Rats}

Niels Hadrup ${ }^{\mathrm{a}, \mathrm{b} *}$, Katrin Loeschner ${ }^{\mathrm{c}}$, Karen Mandrup a, Gitte Ravn-Haren a, Henrik L. Frandsen ${ }^{\text {d, Erik H. Larsen }}{ }^{\mathrm{c}}$, Henrik R. Lam ${ }^{\mathrm{e}}$, Alicja Mortensen ${ }^{\mathrm{a}, \mathrm{b}}$

${ }^{a}$ Division for Food, Disease Prevention and Toxicology, National Food Institute, Technical University of Denmark, Kgs. Lyngby, Denmark; ${ }^{b}$ National Research Center For The Working Environment, Copenhagen, Denmark; ${ }^{c}$ Division for Food Technology, National Food Institute, Technical University of Denmark, Kgs. Lyngby, Denmark; ${ }^{d}$ Research Group for Analytical Food Chemistry, National Food Institute, Technical University of Denmark, Kgs. Lyngby, Denmark, ${ }^{e}$ Environment and Toxicology, DHI, Hørsholm, Denmark.

\section{Postal addresses, telephone numbers and email addresses:}

*Niels Hadrup: National Research Center For The Working Environment, Lersø Parkalle 105, DK-2100 Copenhagen Ø, Denmark, Telephone:+45 391652 14, e-mail: nih@nrcwe.dk

Katrin Loeschner: Division for Food Technology, National Food Institute, Technical University of Denmark, Kemitorvet 201, DK-2800 Kgs. Lyngby, Denmark; e-mail: kals@food.dtu.dkTelephone: +45 35887029

Karen Mandrup: Division for Food, Disease Prevention and Toxicology, National Food Institute, Technical University of Denmark, Kemitorvet 2012800 Kgs. Lyngby, Denmark; e-mail: karenmandrup@gmail.com

Gitte Ravn-Haren: Division for Food, Disease Prevention and Toxicology, National Food Institute, Technical University of Denmark, Kemitorvet 2012800 Kgs. Lyngby, Denmark; e-mail: girh@food.dtu.dk_Telephone: +45 35887600

Henrik L. Frandsen: Research Group for Analytical Food Chemistry, National Food Institute, Technical University of Denmark, Kemitorvet 202, DK-2800 Kgs. Lyngby, Denmark; e-mail: hlafr@food.dtu.dk Telephone: +45 35887597

Erik H. Larsen: Division for Food Technology, National Food Institute, Technical University of Denmark, Kemitorvet 201, DK-2800 Kgs. Lyngby, Denmark; e-mail: erik.huusfeldt.larsen@gmail.com

Henrik R. Lam: Environment and Toxicology, DHI, Agern Alle 5, DK-2970 Hørsholm, Denmark; e-mail: $\underline{\text { hrl@dhigroup.com }}$ 
Alicja Mortensen: National Research Center For The Working Environment, Lersø Parkalle 105, DK-2100 Copenhagen Ø, Denmark, Telephone:+45 391652 95, e-mail: aam@nrcwe.dk

*For correspondence contact Niels Hadrup (handles correspondence at all stages of refereeing, publication and post-publication), nih@nrcwe.dk, National Research Center For The Working Environment, Lersø Parkalle 105, DK-2100 Copenhagen Ø, Denmark). (At the post publication stage add Alicja Mortensen as an alternative correspondence address aam@nrcwe.dk, National Research Center For The Working Environment, Lersø Parkalle 105, DK-2100 Copenhagen Ø, Denmark) 


\section{Subacute Oral Toxicity Investigation of Selenium Nanoparticles and Selenite in Rats}

Selenium (Se) nanoparticles have been proposed as food supplements. However, the particle formulation may exert unexpected toxicity. The aim was therefore to compare toxicity of low doses of Se nanoparticles and the dissolved, ionised Se species selenite. Female rats were dosed orally for 28 days with either: 0.05, 0.5 or $4 \mathrm{mg} \mathrm{Se/kg} \mathrm{body} \mathrm{weight} \mathrm{(bw)/day} \mathrm{as} 20 \mathrm{~nm}$ Se nanoparticles or 0.05 or $0.5 \mathrm{mg}$ $\mathrm{Se} / \mathrm{kg}$ bw/day as sodium selenite. Male rats were dosed $4 \mathrm{mg} \mathrm{Se/kg} \mathrm{bw/day} \mathrm{as} \mathrm{Se}$ nanoparticles. Body weight and clinical appearance were recorded throughout the experiment. At necropsy, blood samples were taken for haematological and clinical chemistry analyses; organ weights were recorded. At the high dose of Se nanoparticles, overt toxicity occurred and the female animals had to be euthanised prematurely, whereas the male animals were reduced in dose. At all doses of Se nanoparticles and at $0.5 \mathrm{mg} \mathrm{Se} / \mathrm{kg}$ bw/day as selenite, a lower body weight gain as compared to vehicle occurred. Relative liver weight was increased for both Se formulations at $0.5 \mathrm{mg}$ Se/kg bw/day. Creatinine clearance and urinary $\mathrm{pH}$ were affected in some Se dosed groups. There were no effects among dosed groups on brain neurotransmitters or on haematological parameters compared with controls. There were no histological changes in the livers of animals exposed to Se nanoparticles or to selenite. Based on effects on body weight and liver weight, selenium nanoparticles and ionic Se exerted similar toxicity. This suggests that a nanoparticle-specific toxicity of Se did not occur.

Keywords: selenium; nanoparticle; sodium selenite; toxicity; subacute 


\section{Introduction}

Selenium (Se) is an essential element, necessary for proper cellular function (Levander 1982, Bulteau and Chavatte 2015). Se has been suggested to be effective in cancer prevention among individuals with low Se status (Vinceti et al. 2014). Se is a constituent of most food supplements with recommended daily doses of typically 50-100 $\mu$ g. The tolerable upper intake level is $300 \mu \mathrm{g}$ /day (SCF 2006). Signs of Se toxicity are e.g. gastrointestinal disorders, irritability, fatigue, hair loss, nail brittleness, dizziness, nausea, concentration difficulties, pulmonary oedema, liver cirrhosis and ultimately mortality (Nelson et al. 1943, Sioris et al. 1980, Köppel et al. 1986, Matoba et al. 1986, Hawkes et al. 1992, Hunsaker et al. 2005, See et al. 2006, Spiller and Pfiefer 2007, Sutter et al. 2008, MacFarquhar et al. 2010, Müller and Desel 2010). The window between intake of Se from food and food supplements and the tolerable upper intake level is narrow. Se nanoparticles (SeNP) are considered to provide a depot formulation of Se through gradual release of dissolved Se from the particle surface. A gradual release formulation has been proposed to be desirable for safer food supplements (Kojouri, Jahanabadi, et al. 2012, Skalickova et al. 2017). Regarding toxicity, the hypothesis we aimed at investigating was whether SeNP have effects analogous to the molecular selenium species used in food supplements or whether they exert any particle specific toxicity. Particles may disrupt biological structures due to their physical form and catalytic reactions may take place on the particle surface. Thus, it is relevant to assess whether particle specific toxicity occurs for Se, and whether toxicity occurs at higher or lower doses as compared to more traditional ionic Se preparations. This has been addressed in a range of studies. SeNP (20$60 \mathrm{~nm}$ in diameter) have been shown to have an acute toxicity seven fold lower than that for selenite in mice based on mortality (Zhang et al. 2001). Furthermore, Zhang et al. found that oral doses of $6 \mathrm{mg}$ Se/kg bw/day as selenite or as SeNP (20-60 nm) for 12 days to mice suppressed weight gain and induced changes in liver enzymes, with selenite exerting the greatest effect (Zhang et al. 2005). Also, at 2 and $4 \mathrm{mg} \mathrm{Se} / \mathrm{kg}$ bw/day, selenite suppressed growth of mice to a greater extent than SeNP (Zhang et al. 2005). Benko et al. found selenite and SeNP (100-500 nm in diameter) to be almost equally toxic considering effects on white blood cell counts after administration of $0.004,0.04$ and 0.4 $\mathrm{mg} \mathrm{Se} / \mathrm{kg}$ bw/day for 14 days (Benko et al. 2012). In a 13-week rat feeding study, only a slight difference in toxicity between the same two Se preparations was observed based on haematology and organ weight; administered doses were $0.1,0.2,0.3$ and $0.4 \mathrm{mg} \mathrm{Se} / \mathrm{kg}$ bw/day as SeNP (20-60 nm in diameter) or selenite and the no observed adverse effect level (NOAEL) was $0.1 \mathrm{mg} / \mathrm{kg}$ bw for selenite as compared to NOAEL of $0.2 \mathrm{mg} / \mathrm{kg}$ bw for SeNP (Jia et al. 2005). Similar toxicity of SeNP and selenite was demonstrated in sheep; an oral dose of $1 \mathrm{mg} / \mathrm{kg}$ Se bw/day of SeNPs (smaller than $220 \mathrm{~nm}$ ) or selenite administered for 10 days resulted in similar effects on serum iron, transferrin expression and increased neutrophil chemotactic activities (Kojouri, Jahanabadi, et al. 2012, Kojouri, Sadeghian, et al. 2012).

To provide further knowledge on the toxicity of SeNP compared to a dissolved, ionised Se species, we used SeNP $20 \mathrm{~nm}$ in diameter and Se in the form of selenite. SeNP was administered at doses ranging from 0.05 (equal to 1.5 fold to the human tolerable 
upper intake level, when converted by difference in body surface area according to (Reagan-Shaw et al. 2008)(low-dose)) via 0.5 (supra-nutritional dose (mid-dose)) to 4 (high-dose) mg Se/kg bw/day. Selenite was administered to rats at equal low- and middoses. The compounds were administered by oral gavage to rats for 28 days. To address general toxicity, standard toxicity parameters were measured. Se toxicity in humans has been reported to include such effects as paraesthesia, memory loss and difficulties of concentration (Clark et al. 1996, Sutter et al. 2008, Aldosary et al. 2012). In order to address whether neurotoxic changes occurred, brain neurotransmitters were measured.

\section{Materials and Methods}

\section{SeNP synthesis and characterisation}

SeNP were synthesised using a method developed by Zhang et al. (Zhang et al. 2001) and the synthesis was based on the reaction of selenite and glutathione in the presence of bovine serum albumin (BSA). The Se in the NPs had an oxidation state of 0. The SeNP were characterised with regard to their physico-chemical characteristics before and after the animal experiment. This included size distribution determined by dynamic light scattering (DLS), size and shape by transmission electron microscopy (TEM), and total Se concentration of the suspension by inductively coupled plasma-mass spectrometry before and after filtration of the suspension through $12 \mathrm{kDa}$ filters (Loeschner et al. 2014). For DLS, undiluted, $400 \mathrm{mg}$ Se/L, SeNP suspension was directly analysed. For TEM analysis, the suspension was diluted 10 fold with ultrapure water, The mode of the volume-based size distribution by DLS was at around $20 \mathrm{~nm}$ (Loeschner et al. 2014). The polydispersity index was in the range of 0.174 to 0.236 and the Z-average in the range of 32 to $38 \mathrm{~nm}$. TEM confirmed the determined diameter and showed that the particles had a spherical shape (Loeschner et al. 2014). A TEM picture of the SeNP suspension can be seen in Figure 1. The Zeta potential of the SeNP in the undiluted suspension (determined by laser Doppler electrophoresis) was in the range of +10 to $20 \mathrm{mV}$ (pH 4).

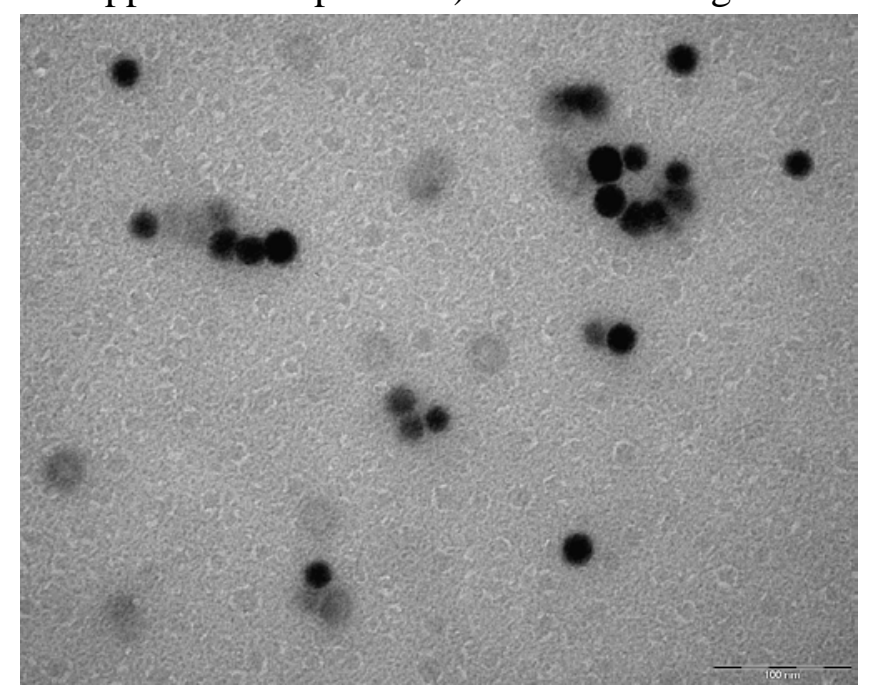

Figure 1. TEM picture of the SeNP suspension 


\section{Study design of the 28-day toxicity study}

Four weeks old Wistar rats (Wistar Hannover Galas) (Taconic M\&B DK-4623, Lille Skensved, Denmark) with specific-pathogen-free health status (SPF), were weight-randomised and allowed to acclimatize for one week. The rats of the same sex were housed two per cage (Macrolon, Techniplats Gazzada S. ar. L., Buguggiate, Italy) with a 12:12-h reversed light/dark cycle with light from 7 p.m. to 7 a.m. The room temperature was $22 \pm 1{ }^{\circ} \mathrm{C}$ and the relative humidity $55 \% \pm 5 \%$. The rats were offered a standard diet (Altromin rat No.1324, Brogården, Gentofte, Denmark) and citric acid acidified tap water (to $\mathrm{pH} 3$ ), to avoid microbiological contamination of drinking water), both ad libitum. The rats were divided into the following treatment groups: 1. Vehicle-BSA (4g/L) control (8 females and 6 males), 2. SeNP low-dose (0.05 mg Se/kg bw/day) (6 females), 3. SeNP mid-dose (0.5 mg Se/kg bw/day) (6 females), 4. SeNP high-dose (4 mg Se/kg bw/day) (8 females and 6 males), 5 . Vehicle- $\mathrm{H}_{2} \mathrm{O}$ control (8 females), 6 . Selenite low-dose (0.05 mg Se/kg bw/day) (8 females) 7. Selenite mid-dose ( $0.5 \mathrm{mg} \mathrm{Se} / \mathrm{kg}$ bw/day) (8 females). The vehicle-BSA group (1) served as control group for the SeNP dosed animals and the vehicle- $\mathrm{H}_{2} \mathrm{O}$ group (5) served as control group for selenite dosed animals. The reason for having two control groups is that the SeNP had to be stabilised in BSA; whereas the addition of BSA was not compatible with the selenite. This is because the selenium atom of selenite may passively become incorporated into the BSA molecule in place of its natural content of sulfur in methionine. This would negatively affect the actual selenite concentration in solution before this solution was administered to the animals. At 5 weeks of age dose administration was done by oral gavage at a volume of $10 \mathrm{~mL} / \mathrm{kg}$ bw/day. Selenite was administered as sodium selenite. Clinical cage-side observations were performed twice daily. Body weight was recorded three times per week. Feed and water intake was recorded at weekly intervals. The feed and water intakes were recorded per cage and thus per two animals. It was thus, when calculating intakes, estimated that the animals in each cage ate and drank equal amounts. At day 14 of dosing the animals were placed individually for 24 hours in metabolism cages for collection of urine and faeces. The urine samples were cooled by sampling on dryice and subsequently stored at $-80{ }^{\circ} \mathrm{C}$ until analyses. During the stay in metabolism cages the rats did not have access to feed. At the end of the 28-day administration period the rats were anaesthetised in $\mathrm{O}_{2} / \mathrm{CO}_{2}$ and decapitated. Blood for haematology and clinical chemistry was collected from the neck wound in heparinEDTA tubes. Plasma was prepared by centrifugation at $1000 \mathrm{x}$ g at $4{ }^{\circ} \mathrm{C}$ for $10 \mathrm{~min}$. Following necropsy adrenals, liver, spleen, kidneys, testes, epididymis, ovaries, thymus, mesenteric lymph nodes, heart and brain were removed and weighed. Liver specimens from all animals surviving to the terminal sacrifice were fixed in $4 \%$ neutral buffered formaldehyde, paraffin-embedded and three micrometre-thick sections were stained with haematoxylin and eosin for histological examination. Brains from all treatment groups were processed for neurotransmitter analysis as described below. The Animal experiments were carried out in accordance with the guidelines stipulated by the National Food Institute’s Animal Welfare Committee. 
Ethical approval was given by the Danish Animal Experiments Inspectorate (approval number 2004/561-917).

\section{Haematology and clinical biochemistry}

White blood cell (WBC) counts, erythrocyte (RBC) counts, haemoglobin concentration (HGB), haematocrit (HCT), platelet (PLT) counts, mean corpuscular volume (MCV), mean corpuscular haemoglobin (MCH), mean corpuscular haemoglobin concentration (MCHC), red cell distribution width (RDW), and mean platelet volume (MPV) were determined in all treatment groups using an Animal Blood Counter Vet (Horiba ABX, Montpellier, France). Blood smears were prepared and stained with May-Grünwald and Giemsa. Differential counting of lymphocytes, monocytes, neutrophil granulocytes, eosinophil granulocytes and basophil granulocytes was done manually by assessing distribution of a total of 100 cells from each animal from the following treatment groups: Vehicle-BSA (females and males), SeNP mid-dose, SeNP high-dose (males) and selenite mid-dose. Differentiation was based on morphologic criteria as described in Bailly and Duprat (Bailly and Duprat 1990). The following clinical biochemical plasma parameters were measured on a Hitachi 912 Automatic Analyzer (Boehringer Ingelheim, Ingelheim am Rhein, Germany) using commercially available kits purchased from Roche/Hitachi (IN, USA): Alanine aminotransferase (ALT) (prod. no. 10851132 216), cholesterol (kit prod. no. 11489232 216), total protein (prod. no.11553836 316), alkaline phosphatase (ALP) (prod. no. 10816388 216), glucose (prod. no. 11447513 216), urea ( prod. no. 11489364), creatinine (prod. no. 1104084 216). Urinary glucose, bilirubin, ketones, specific gravity, blood, $\mathrm{pH}$, total protein, urobilinogen, nitrite, and leukocytes were monitored by use of Multistix 10 SG (Prod. no. 2300, Siemens Health Care Diagnostics, NY, USA).

\section{Neurotransmitter analyses}

Dopamine, noradrenaline and serotonin were measured as previously described (Hadrup et al. 2012). A brief description is as follows, brain tissue was homogenised under ice-cold conditions in $0.32 \mathrm{M}$ sucrose, ( $9 \mathrm{~mL} /$ whole brain) using an UltraTurrax T25 homogeniser (IKA, Staufen, Germany). Then the homogenate was de-proteinised using a 1:1 volume of $0.2 \mathrm{M}$ perchloric acid $\left(\mathrm{HClO}_{4}\right)$ followed by centrifugation ( $20 \mathrm{~min}, 0-4{ }^{\circ} \mathrm{C}, 10000 \mathrm{xg}$ ). For the noradrenaline and dopamine measurements, 3,4-dihydroxybenzylamine (Sigma, D 7012) was added as internal standard. Next, the samples were purified on aluminium oxide (Anton and Sayre 1962) followed by elution with $0.2 \mathrm{M} \mathrm{HClO}_{4}$. For the analysis of 5-HT, N-๘methyl-5-HT (Sigma, M 1514) was added as internal standard. The neurotransmitters were measured using high performance liquid chromatography (HPLC) with electrochemical detection. The instrumentation consisted of a Hewlett-Packard Ti-SERIES 1100 liquid chromatograph equipped with an ESA MD-150 analytical column ( $3 \mathrm{~mm}$ ID $15 \mathrm{~cm}, \mathrm{C}_{18}, 5 \mathrm{~mm}$ ). Separation was achieved with a $5 \%(\mathrm{v} / \mathrm{v})$ acetonitrile modified $75 \mathrm{mM}$ sodium phosphate buffer (1.7 octenylsulfonic acid, $100 \mathrm{~mL}$ triethylamine/L and 25 mM EDTA; pH 3). Signals 
were detected using a dual potentiostat electrochemical detector (ESA Model 5200A Coulochem II and ESA Model 5011 high sensitivity analytical cell with an E1 of $150 \mathrm{mV}$ and an E2 of $+220 \mathrm{mV}$; guard cell potential: +350 mV, Chelmsford, MA, USA).

\section{Statistical analyses}

The statistical package used was Graph Pad Prism version 4.0 by GraphPad Software (San Diego, CA, USA). Data were tested for normal distribution using the KolmogorovSmirnov test. In case of absence of normal distribution data were transformed using the $\log _{10}$ function before a second round of testing for normal distribution. Differences in mean values of normal distributed data were tested using one-way ANOVA with Dunnet's post-test for vehicle-BSA control vs. SeNP groups and separately for $\mathrm{H}_{2} \mathrm{O}$ control vs. selenite groups. A Student's t-test was used to test for differences of mean values for male BSA control vs. male SeNP high-dose. In case of absence of normal distribution tests the Kruskal Wallis followed by Dunn's multiple comparisons test was applied. Data were expressed as mean \pm SEM. P values of less than 0.05 were considered statistically significant.

\section{Results}

In the SeNP low-dose female group both body weight gain and body weight at the end of the study were lower compared to the vehicle control group. In the SeNP mid-dose female group only body weight gain was lower as compared to the vehicle controls (Figure 2A, Table 1). Regarding selenite female groups, only body weight gain in the mid-dose group was lower (Figure 2B, Table 1). Female rats from the SeNP high-dose group in comparison to the control group did not gain weight (Fig. 2A) during the first week, were less motorically active and local alopecia indicative of hair loss was recorded. Therefore the dose of SeNP was reduced from 4 to $1 \mathrm{mg} \mathrm{Se} / \mathrm{kg}$ bw/day from day 9 to the end of the experiment. As males receiving SeNP high-dose started presenting the same clinical appearance and low weight gain (Fig 2C) the SeNP dose was reduced from 4 to $1 \mathrm{mg}$ $\mathrm{Se} / \mathrm{kg}$ bw/day from day 11 . Four female rats and two male rats in the high-dose group did not receive SeNPs from day 11 due to the severity of the clinical signs. On day 16, all female rats and two male rats in the SeNP high-dose group were euthanised because of the disturbed clinical condition and necropsy was conducted. The remaining four male rats proceeded on the daily dose of $1 \mathrm{mg}$ Se/kg bw as SeNP until the end of the experiment, and a mean dose received during the dosing period was calculated to $2.2 \mathrm{mg}$ SeNP/kg bw/day based on 11 days with $4 \mathrm{mg} \mathrm{SeNP/kg} \mathrm{bw} \mathrm{and} 17$ days with $1 \mathrm{mg} \mathrm{Se/kg}$ bw as SeNP. Feed and water intake were not affected in any of the groups of rats surviving to the scheduled termination (Table 1 ). 
A)

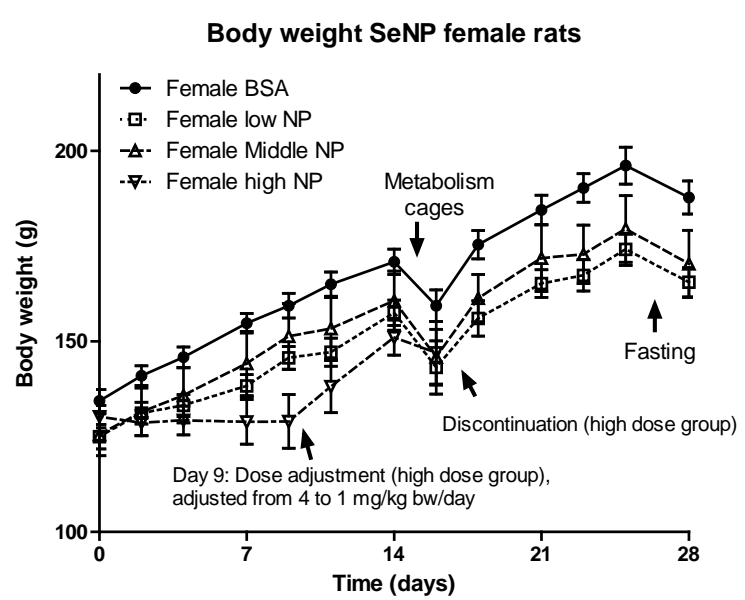

B)

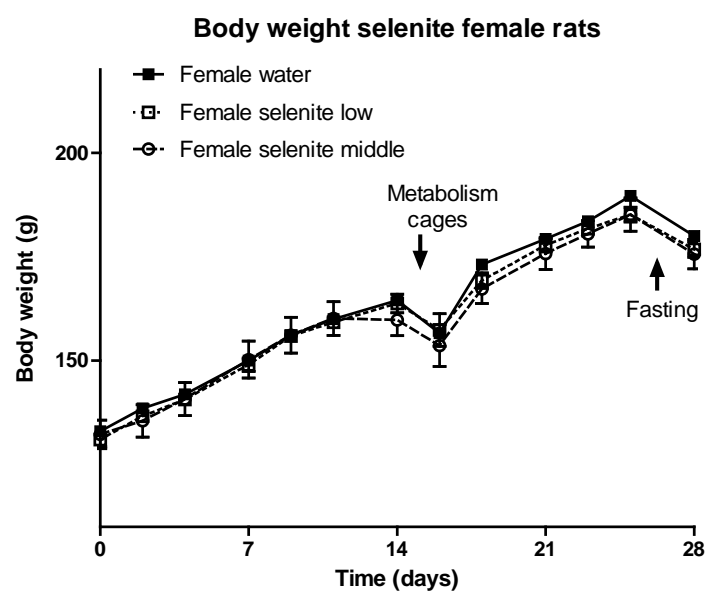

C)

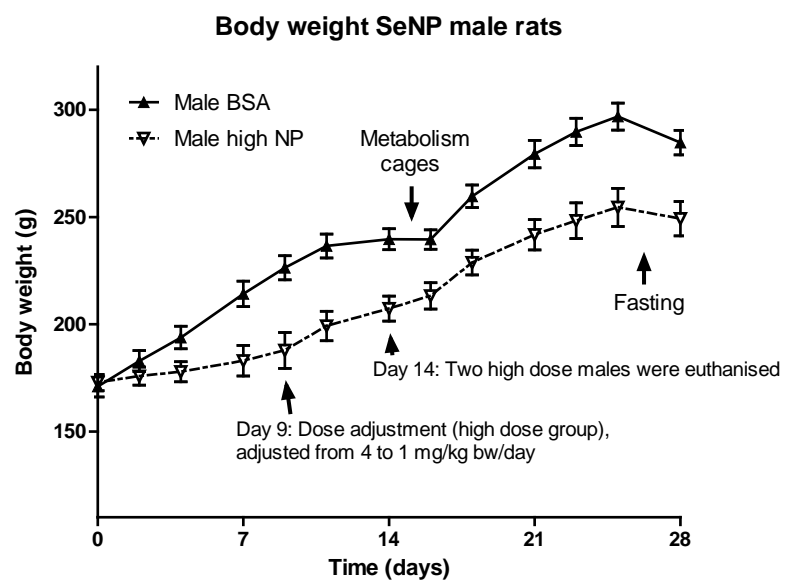

Figure 2. Body weight of rats administered SeNP or selenite. Rats received by gavage SeNP Low-dose (0.05 mg Se/kg bw/day), SeNP mid-dose (0.5 mg Se/kg bw/day) (6 females), SeNP high-dose (4 mg Se/kg bw/day) (Panel A and B), selenite low-dose (0.05 $\mathrm{mg} \mathrm{Se} / \mathrm{kg}$ bw/day) or selenite mid-dose (0.5 mg Se/kg bw/day) (Panel C). Body weight was recorded three times per week. Animals fasted during the last 24 hours of the experimental period, as indicated on graphs. Vehicles were either water or BSA in water. Data are mean \pm SEM. Numerical values and statistics can be found in Table 1 .

Haematology values were not affected among the treatment groups (Table 2). Regarding plasma and urine biochemical parameters, only plasma creatinine was decreased in the 
SeNP mid-dose female group while creatinine excretion and clearance were increased for high-SeNP dosed male rats. Urine analysis revealed an increase in $\mathrm{pH}$ in urine collected from the selenite mid-dose female group and from the SeNP high-dose male rats. No effects were found in the brain concentration of any of the investigated neurotransmitters, dopamine, noradrenaline or 5-HT (Table 3).

Absolute liver weight was decreased in SeNP low-dose females and increased in selenite mid-dose females (Table 4). Relative liver weight was increased in both SeNP high-dose males and SeNP mid-dose females as well as in selenite mid-dose females (Table 5). In SeNP high dose males absolute testes weight as well as absolute and relative weights of the epididymis were decreased (Tables 4 and 5).

Histological examination of the livers from females exposed to low- and mid-doses of either SeNP or selenite and of males from SeNP high-dose group did not reveal any changes as compared to the respective controls.

\section{Discussion}

We aimed at assessing the toxic potential of SeNP and whether the toxicity of this formulation differed from that of the dissolved Se-containing molecule, selenite. Overt toxicity occurred at the highest dose. Body weight gain changes, changes in liver weight as well as some biochemical endpoints occurred at mid and low doses. Based on a decrease in body weight gain our data suggested that the lowest SeNP dose (0.05 mg $\mathrm{Se} / \mathrm{kg}$ bw) was a lowest observed adverse effect level (LOAEL). This suggested that the no observed adverse effect level (NOAEL) for SeNP was even lower. With respect to literature data the toxicity of selenite and of SeNP $(100-500 \mathrm{~nm})$ was investigated in mice at doses of $0.004,0.04$ and $0.4 \mathrm{mg} \mathrm{Se} / \mathrm{kg}$ bw. Equal toxicity was observed as both forms induced higher relative heart weight at lowest dose and decreased the number of white blood cell counts at the two lowest doses (Benko et al. 2012). Jia et al. administered SeNP or selenite to rats at 0.14 to $0.48 \mathrm{mg} \mathrm{Se} / \mathrm{kg}$ bw/day, and based on haematology results and organ weight changes, identified a NOAEL of $0.22 \mathrm{mg} \mathrm{Se} / \mathrm{kg}$ bw/day and $0.14 \mathrm{mg} \mathrm{Se} / \mathrm{kg}$ bw/day for SeNP and selenite, respectively (Jia et al. 2005). Kojouri et al. found effects on serum iron, transferrin expression and increased neutrophil chemotactic activities in sheep at $1 \mathrm{mg} \mathrm{Se} / \mathrm{kg}$ bw/day of SeNP dosed for 10 days (Kojouri et al. 2012a; Kojouri et al. 2012b). Thus, based on previously published studies on the toxicity of Se, a LOAEL of both SeNP and selenite could be set as low as $0.004 \mathrm{mg} \mathrm{Se} / \mathrm{kg}$ bw/day given that increased relative heart weight and lowered white blood cells are considered as adverse effects (Benko et al. 2012). In our study we found a LOAEL of $0.05 \mathrm{mg} \mathrm{Se/kg} \mathrm{bw/day,}$ which was based on reduction in body weight gain. This LOAEL was about a factor of 10 higher than that reported by Kojouri et al. and could possibly be ascribed to interspecies differences, differences in formulation of SeNP and in sensitivities of endpoints used in the two studies.

Selenite was included to compare the nanoparticle formulation with that of selenite, a commonly used Se species in food supplements. Selenite decreased body weight gain only in animals that received the mid-dose of this Se preparation. At this dose the relative liver weight was also increased as observed also for SeNP. An increase in urinary $\mathrm{pH}$ at the mid-dose was a finding not seen for rats dosed with SeNP. Altogether 
these data suggest a NOAEL of $0.05 \mathrm{mg}$ Se/kg bw for selenite. We note that this dose is 1.5 fold the human tolerable upper intake level of Se when converted by difference in body surface area; And 10 fold the recommended human high level when considered per body weight. And thus, based on our data, the tolerable upper intake levels could be considered to be too high, as assessment factors of at least 100 would be needed to calculate an acceptable daily intake based on a NOAEL in $\mathrm{mg} / \mathrm{kg}$ bw.

When comparing the two Se formulations both had effects on body weight gain and relative liver weight, suggesting that they targeted the same endpoints. This is in line with the previously published bio-distribution study of Se in the investigated animals, which demonstrated equal distribution to organs of Se following dosage with SeNPs or selenite (Loeschner et al. 2014). More specifically, for Se-containing metabolites in urine, the oral exposure to SeNPs or selenite led to excretion of the same Se-containing metabolites, namely seleno-sugars. This suggested that both forms were metabolised and excreted similarly (Loeschner et al. 2014). Moreover, in a previous study based on the same animal experiment we found that both Se formulations displayed similar effects on the general urine metabolome as indicated by partial least squares discriminant analyses, with specific differences in such putative identified metabolites as decanedioic acid and hydroxydecanedioic acid (Hadrup et al. 2016). Data from other studies show that ionic forms of Se exert toxicity at lower doses as compared to SeNPs (Zhang et al. 2001, 2005, 2008, Jia et al. 2005, Wang et al. 2007), or that equal or almost equal effects occur following dosage of the two formulations (Benko et al. 2012, Kojouri, Jahanabadi, et al. 2012, Kojouri, Sadeghian, et al. 2012). Combined with results from our study, the available data did not lead to any firm conclusion on whether SeNPs are less or more toxic as compared to dissolved $\mathrm{Na}$ selenite, i.e. a specific effect derived from the nanoparticulate form of Se cannot be substantiated.

We note that results from our study and from published results showed that the same toxicity endpoints are affected by both SeNPs and dissolved ionic Se species (Zhang et al. 2001, 2005, 2008, Jia et al. 2005, Wang et al. 2007, Benko et al. 2012, Kojouri, Sadeghian, et al. 2012, Hadrup et al. 2016). An explanation for this could be that SeNP are dissolved in the mammalian body to exert an effect similar to that observed for dissolved selenite.

In conclusion, SeNP and the ionised selenite at the same Se dose administered orally exerted effects on body weight gain and on liver weight in rats. Based on these endpoints, however, the low dose of $0.05 \mathrm{mg}$ Se/kg bw was considered as a LOAEL for SeNP and as a NOAEL for selenite. Overall SeNPs and selenite exerted similar toxicity with respect to endpoints and dose, suggesting that a nanoparticle-specific toxicity did not occur.

\section{Acknowledgements}

The authors wish to thank The Danish AgriFish Agency for funding the project. Anne Ørngreen, Maja Danielsen, Eva Ferdinansen, Elise E. Navntoft, Eigil V. Frank, Kenneth R. Worm, Sarah G. Simonsen, Annette Landin, Karen Roswall, Ulla Baroudy, Vibeke Kjær, Nehad Moradian are thanked for excellent technical assistance. Finally, we thank Dr Xueyun Gao, Institute for High Energy Physics, Chinese Academy of Sciences, Beijing, China for the synthesis of the BSA-stabilised SeNPs. 


\section{Declaration of interest statement}

The authors report no conflict of interest.

\section{References}

Aldosary, B.M., Sutter, M.E., Schwartz, M., and Morgan, B.W., 2012. Case Series Of Selenium Toxicity From A Nutritional Supplement. Clinical Toxicology.

Bailly, Y. and Duprat, P., 1990. Normal blood cell values, rat. In: T.C. Jones, J.M. Ward, U. Mohr, and R.D. Hunt, eds. Hemopoietic System. Berlin: Springer-Verlag, 27-38.

Benko, I., Nagy, G., Tanczos, B., Ungvari, E., Sztrik, A., Eszenyi, P., Prokisch, J., and Banfalvi, G., 2012. Subacute toxicity of nano-selenium compared to other selenium species in mice. Environ Toxicol Chem, 31 (12), 2812-2820.

Bulteau, A.-L. and Chavatte, L., 2015. Update on selenoprotein biosynthesis. Antioxidants \& redox signaling, 23 (10), 775-94.

Clark, R.F., Strukle, E., Williams, S.R., and Manoguerra, A.S., 1996. Selenium poisoning from a nutritional supplement. JAMA : the journal of the American Medical Association.

Hadrup, N., Loeschner, K., Mortensen, A., Sharma, A.K., Qvortrup, K., Larsen, E.H., and Lam, H.R., 2012. The similar neurotoxic effects of nanoparticulate and ionic silver in vivo and in vitro. NeuroToxicology, 33 (3), 416-423.

Hadrup, N., Loeschner, K., Skov, K., Ravn-Haren, G., Larsen, E.H., Mortensen, A., Lam, H.R., and Frandsen, H.L., 2016. Effects of 14-day oral low dose selenium nanoparticles and selenite in rat-as determined by metabolite pattern determination. Peer J, 4, e2601.

Hawkes, W.C., Willhite, C.C., Craig, K.A., Omaye, S.T., Cox, D.N., Choy, W.N., and Hendrickx, A.G., 1992. Effects of excess selenomethionine on selenium status indicators in pregnant long-tailed macaques (Macaca fascicularis). Biological Trace Element Research, 35 (3), 281-297.

Hunsaker, D.M., Spiller, H.A., and Williams, D., 2005. Acute selenium poisoning: suicide by ingestion. Journal of forensic sciences.

Jia, X., Li, N., and Chen, J., 2005. A subchronic toxicity study of elemental Nano-Se in Sprague-Dawley rats. Life Sciences, 76 (17), 1989-2003.

Kojouri, G.A., Jahanabadi, S., Shakibaie, M., Ahadi, A.M., and Shahverdi, A.R., 2012. Effect of selenium supplementation with sodium selenite and selenium nanoparticles on iron homeostasis and transferrin gene expression in sheep: a preliminary study. Research in Veterinary Science, 93 (1), 275-278.

Kojouri, G.A., Sadeghian, S., Mohebbi, A., and Mokhber Dezfouli, M.R., 2012. The effects of oral consumption of selenium nanoparticles on chemotactic and respiratory burst activities of neutrophils in comparison with sodium selenite in sheep. Biological Trace Element Research, 146 (2), 160-166.

Köppel, C., Baudisch, H., Beyer, K.H., Klöppel, I., and Schneider, V., 1986. Fatal poisoning with selenium dioxide. Journal of toxicology. Clinical toxicology. 
Levander, O.A., 1982. Clinical Consequences of Low Selenium Intake and Its Relationship to Vitamin-E. Annals of the New York Academy of Sciences, 393 (Sep), 70-82.

Loeschner, K., Hadrup, N., Hansen, M., Pereira, S.A., Gammelgaard, B., Moller, L.H., Mortensen, A., Lam, H.R., and Larsen, E.H., 2014. Absorption, distribution, metabolism and excretion of selenium following oral administration of elemental selenium nanoparticles or selenite in rats. Metallomics, 6 (2), 330-337.

MacFarquhar, J.K., Broussard, D.L., Melstrom, P., Hutchinson, R., Wolkin, A., Martin, C., Burk, R.F., Dunn, J.R., Green, A.L., Hammond, R., Schaffner, W., and Jones, T.F., 2010. Acute selenium toxicity associated with a dietary supplement. Archives of internal medicine, 170 (3), 256-261.

Matoba, R., Kimura, H., Uchima, E., Abe, T., Yamada, T., Mitsukuni, Y., and Shikata, I., 1986. An autopsy case of acute selenium (selenious acid) poisoning and selenium levels in human tissues. Forensic science international.

Müller, D. and Desel, H., 2010. Acute selenium poisoning by paradise nuts (Lecythis ollaria). Human \& experimental toxicology, 29 (5), 431-434.

Nelson, A., Fitzhugh, O., and Calvery, H., 1943. Liver Tumors Following Cirrhosis Caused by Selenium in Rats. Cancer Research, 3, 230-236.

Reagan-Shaw, S., Nihal, M., and Ahmad, N., 2008. Dose translation from animal to human studies revisited. FASEB Journal, 22 (3), 659-661.

SCF, 2006. Tolerable Upper Intake Levels for Vitamins and Minerals. Scientific Committee on Food Scientific Panel on Dietetic Products, Nutrition and Allergies.

See, K.A., Lavercombe, P.S., Dillon, J., and Ginsberg, R., 2006. Accidental death from acute selenium poisoning. Medical Journal of Australia, 185 (7), 388-389.

Sioris, L., Guthrie, K., and Pentel, P., 1980. Acute Selenium Poisoning. In: Veterinary and human toxicology. 22, 364.

Skalickova, S., Milosavljevic, V., Cihalova, K., Horky, P., Richtera, L., and Adam, V., 2017. Selenium nanoparticles as a nutritional supplement. Nutrition (Burbank, Los Angeles County, Calif.), 33, 83-90.

Spiller, H.A. and Pfiefer, E., 2007. Two fatal cases of selenium toxicity. Forensic Science International, 171 (1), 67-72.

Sutter, M.E., Thomas, J.D., Brown, J., and Morgan, B., 2008. Selenium toxicity: A case of selenosis caused by a nutritional supplement. Annals of Internal Medicine.

Vinceti, M., Dennert, G., Crespi, C.M., Zwahlen, M., Brinkman, M., Zeegers, M.P.A., Horneber, M., D’Amico, R., and Del Giovane, C., 2014. Selenium for preventing cancer. The Cochrane database of systematic reviews, (3), CD005195.

Wang, H., Zhang, J., and Yu, H., 2007. Elemental selenium at nano size possesses lower toxicity without compromising the fundamental effect on selenoenzymes: comparison with selenomethionine in mice. Free Radical Biology and Medicine, 42 (10), 1524-1533.

Zhang, J., Wang, H., Yan, X., and Zhang, L., 2005. Comparison of short-term toxicity between Nano-Se and selenite in mice. Life Sciences, 76 (10), 1099-1109.

Zhang, J., Wang, X., and Xu, T., 2008. Elemental selenium at nano size (Nano-Se) as a potential chemopreventive agent with reduced risk of selenium toxicity: 
comparison with se-methylselenocysteine in mice. Toxicological Sciences, 101 (1), 22-31.

Zhang, J.S., Gao, X.Y., Zhang, L.D., and Bao, Y.P., 2001. Biological effects of a nano red elemental selenium. Biofactors, 15 (1), 27-38. 


\section{Tables}

Table 1. Body weight, water and feed intake in rats treated orally by gavage for 28 days with SeNP or selenite

\begin{tabular}{|c|c|c|c|c|c|c|c|c|}
\hline \multirow[b]{3}{*}{$\begin{array}{l}\text { Dose (mg/kg bw/day) } \\
\text { end) }\end{array}$} & \multicolumn{6}{|l|}{ Females } & \multicolumn{2}{|l|}{ Males } \\
\hline & Vehicle-BSA & $\begin{array}{l}\text { SeNP } \\
\text { low-dose }\end{array}$ & $\begin{array}{l}\text { SeNP } \\
\text { mid-dose }\end{array}$ & Vehicle- $\mathrm{H}_{2} \mathrm{O}$ & $\begin{array}{l}\text { Selenite } \\
\text { low-dose }\end{array}$ & $\begin{array}{l}\text { Selenite } \\
\text { mid-dose }\end{array}$ & Vehicle-BSA & $\begin{array}{l}\text { SeNP } \\
\text { high-dose }\end{array}$ \\
\hline & $0(\mathrm{n}=8)$ & $0.05(n=6)$ & $0.5(n=6)$ & $0(\mathrm{n}=8)$ & $0.05(n=8)$ & $0.5(n=8)$ & $0(n=6)$ & $4 \quad(n=4$ at \\
\hline Body wt. start (g) & $134 \pm 8$ & $125 \pm 8$ & $126 \pm 13$ & $133 \pm 8$ & $131 \pm 5$ & $132 \pm 10$ & $171 \pm 12$ & $176 \pm 7$ \\
\hline Body wt. end (g) & $188 \pm 12$ & $166 \pm 9 *$ & $170 \pm 22$ & $180 \pm 11$ & $177 \pm 5$ & $175 \pm 10$ & $285 \pm 14$ & $249 \pm 16^{\dagger \dagger}$ \\
\hline Body wt. gain (g) & $54 \pm 9$ & $41 \pm 5 * * *$ & $45 \pm 11^{* *}$ & $47 \pm 7$ & $46 \pm 7$ & $44 \pm 4^{\S}$ & $114 \pm 14$ & $74 \pm 16^{\dagger+\dagger}$ \\
\hline Feed intake (g/animal/day) & $15 \pm 0.3$ & $13 \pm 1$ & $14 \pm 1$ & $15 \pm 0.4$ & $14 \pm 0.4$ & $15 \pm 1$ & $17 \pm 4$ & $17 \pm 2$ \\
\hline $\begin{array}{l}\text { Relative feed intake } \\
\text { (g/kg bw/day) }\end{array}$ & $83 \pm 2$ & $79 \pm 3$ & $81 \pm 5$ & $84 \pm 6$ & $81 \pm 2$ & $83 \pm 3$ & $60 \pm 11$ & $69 \pm 9$ \\
\hline $\begin{array}{l}\text { Water intake } \\
\text { (mL/animal/day) }\end{array}$ & $24 \pm 2$ & $20 \pm 1$ & $23 \pm 3$ & $22 \pm 1$ & $22 \pm 5$ & $17 \pm 2$ & $33 \pm 4$ & $27 \pm 1$ \\
\hline Relative water intake & $128 \pm 8$ & $124 \pm 6$ & $133 \pm 22$ & $123 \pm 11$ & $121 \pm 29$ & $97 \pm 14$ & $115 \pm 8$ & $111 \pm 4$ \\
\hline
\end{tabular}

$(\mathrm{mL} / \mathrm{kg}$ bw/day)

Body weight gain was analysed by one-way-ANOVA taking all time points into consideration. *indicates significance by one-way ANOVA followed by Dunnet's post-testfor vehiclevs. SeNP 0.05 and SeNP $0.5 \mathrm{mg} / \mathrm{kg}$ bw/day in the female group. ${ }^{\dagger}$ indicates significance by t-test vs. male vehicle. Data are mean $\pm \mathrm{SD}$ 
Table 2. Hematology in rats treated orally by gavage for 28 days with SeNP or selenite

\begin{tabular}{|c|c|c|c|c|c|c|c|c|}
\hline Dose (mg/kg bw/day) & $\begin{array}{l}\text { Females } \\
\text { Vehicle-BSA } \\
0(n=8)\end{array}$ & $\begin{array}{l}\text { SeNP } \\
\text { low-dose } \\
0.05(n=6)\end{array}$ & $\begin{array}{l}\text { SeNP } \\
\text { mid-dose } \\
0.5(n=6)\end{array}$ & $\begin{array}{l}\text { Vehicle- } \mathrm{H}_{2} \mathrm{O} \\
0(\mathrm{n}=8)\end{array}$ & $\begin{array}{l}\text { Selenite } \\
\text { low-dose } \\
0.05(n=8)\end{array}$ & $\begin{array}{l}\text { Selenite } \\
\text { mid-dose } \\
0.5(n=8)\end{array}$ & $\begin{array}{l}\text { Males } \\
\text { Vehicle-BSA } \\
0(n=6)\end{array}$ & $\begin{array}{l}\text { SeNP } \\
\text { high-dose } \\
4 \text { ( } \mathrm{n}=4 \text { at end) }\end{array}$ \\
\hline WBC $\quad(10(9) / 1)$ & $3.8 \pm 1.4$ & $4.4 \pm 1.9$ & $4.4 \pm 1.3$ & $5.2 \pm 1.1$ & $5.0 \pm 1.4$ & $5.2 \pm 2.0$ & $4.8 \pm 1.1$ & $5.9 \pm 1.5$ \\
\hline L (\%) & $85 \pm 5$ & & $84 \pm 7$ & & $83 \pm 8$ & & $84 \pm 4$ & $85 \pm 5$ \\
\hline M (\%) & $2.3 \pm 0.8$ & & $2.5 \pm 2.4$ & & $3.1 \pm 1.7$ & & $2.5 \pm 1.3$ & $2.1 \pm 0.5$ \\
\hline N (\%) & $12 \pm 5$ & & $12 \pm 5$ & & $13 \pm 6$ & & $13 \pm 4$ & $13 \pm 5$ \\
\hline E (\%) & $0.5 \pm 0.4$ & & $1.3 \pm 1.2$ & & $1.3 \pm 1.3$ & & $0.7 \pm 0.3$ & $0.6 \pm 0.6$ \\
\hline B (\%) & $0.3 \pm 0.6$ & & $0.1 \pm 0.3$ & & $0.3 \pm 0.5$ & & $0.3 \pm 0.5$ & $0.0 \pm 0.0$ \\
\hline RBC (10(12)/L) & $7.5 \pm 0.3$ & $7.7 \pm 0.5$ & $7.6 \pm 0.4$ & $7.8 \pm 0.6$ & $7.7 \pm 0.3$ & $7.5 \pm 0.5$ & $8.1 \pm 0.4$ & $8.0 \pm 0.5$ \\
\hline HGB (mM) & $9.3 \pm 0.2$ & $9.6 \pm 0.3$ & $9.4 \pm 0.5$ & $9.5 \pm 0.5$ & $9.4 \pm 0.3$ & $9.3 \pm 0.4$ & $9.7 \pm 0.5$ & $9.2 \pm 0.5$ \\
\hline НСТ (\%) & $42.2 \pm 0.9$ & $43.0 \pm 2.6$ & $42.3 \pm 2.7$ & $43.2 \pm 2.4$ & $42.7 \pm 1.4$ & $42.0 \pm 2.3$ & $44.7 \pm 2.1$ & $43.2 \pm 2.9$ \\
\hline $\operatorname{PLT}(10(9) / l)$ & $824 \pm 93$ & $664 \pm 147$ & $683 \pm 132$ & $771 \pm 57$ & $780 \pm 121$ & $738 \pm 83$ & $682 \pm 85$ & $661 \pm 245$ \\
\hline MPV (fL) & $6.1 \pm 0.1$ & $6.1 \pm 0.2$ & $6.0 \pm 0.1$ & $6.1 \pm 0.2$ & $6.1 \pm 0.2$ & $6.1 \pm 0.2$ & $6.4 \pm 0.2$ & $6.2 \pm 0.4$ \\
\hline RDW (\%) & $12.2 \pm 0.6$ & $11.7 \pm 0.8$ & $11.9 \pm 0.2$ & $11.8 \pm 0.3$ & $11.9 \pm 0.3$ & $12.3 \pm 0.4$ & $12.7 \pm 0.6$ & $13.3 \pm 0.4$ \\
\hline MCV (fL) & $56.0 \pm 1.2$ & $55.8 \pm 0.8$ & $56.0 \pm 1.3$ & $55.8 \pm 1.5$ & $55.5 \pm 0.8$ & $56.3 \pm 1.3$ & $55.5 \pm 1.9$ & $54.3 \pm 2.5$ \\
\hline $\mathrm{MCH} \quad(\mathrm{fmol})$ & $19.8 \pm 0.7$ & $19.9 \pm 0.9$ & $19.9 \pm 0.9$ & $19.7 \pm 0.8$ & $19.6 \pm 0.4$ & $19.9 \pm 1.0$ & $19.2 \pm 0.8$ & $18.4 \pm 0.6$ \\
\hline MCHC (mM) & $35.3 \pm 1.0$ & $35.6 \pm 1.3$ & $35.6 \pm 1.3$ & $35.3 \pm 0.8$ & $35.4 \pm 0.7$ & $35.5 \pm 1.1$ & $34.6 \pm 0.6$ & $34.0 \pm 0.5$ \\
\hline
\end{tabular}

WBC: White blood cells, RBC: erythrocytes, HGB: haemoglobin concentration, RDW: Red cell distribution width, MPV: Mean platelet volume, Hct: haematocrit, PLT: Platelets, MCV: Mean corpuscular volume, MCH: Mean corpuscular haemoglobin, MCHC: Mean corpuscular haemoglobin Concentration, L: Lymphocytes, M: Monocytes, N: Neutrophil granulocytes, E: Eosinophil granulocytes, B: Basophil granulocytes. For leukocyte distribution 100 cells from each animal were counted. Data are mean $\pm \mathrm{SD}$. There were no statistically significant differences. 
Table 3. Clinical biochemical and brain neurotransmitter levels in rats treated orally by gavage for 28 days with SeNP or selenite

\begin{tabular}{|c|c|c|c|c|c|c|c|c|}
\hline \multirow[b]{3}{*}{$\begin{array}{l}\text { Dose (mg/kg bw/day) } \\
\text { end) }\end{array}$} & \multicolumn{5}{|l|}{ Females } & \multicolumn{3}{|c|}{ Males } \\
\hline & Vehicle-BSA & $\begin{array}{l}\text { SeNP } \\
\text { low-dose }\end{array}$ & $\begin{array}{l}\text { SeNP } \\
\text { mid-dose }\end{array}$ & Vehicle- $\mathrm{H}_{2} \mathrm{O}$ & $\begin{array}{l}\text { Selenite } \\
\text { low-dose }\end{array}$ & $\begin{array}{l}\text { Selenite } \\
\text { mid-dose }\end{array}$ & Vehicle-BSA & $\begin{array}{l}\text { SeNP } \\
\text { high-dose }\end{array}$ \\
\hline & $0(n=8)$ & $0.05(\mathrm{n}=6)$ & $0.5(\mathrm{n}=6)$ & $0(\mathrm{n}=8)$ & $0.05(n=8)$ & $0.5(\mathrm{n}=8)$ & $0(n=6)$ & $4(n=4$ at \\
\hline $\mathrm{ALT}(\mathrm{u} / \mathrm{L})$ & $53 \pm 14$ & $47 \pm 17$ & $55 \pm 18$ & $53 \pm 21$ & $60 \pm 22$ & $62 \pm 16$ & $69 \pm 8$ & $90 \pm 23$ \\
\hline Cholesterol (mM) & $1.8 \pm 0.5$ & $1.5 \pm 0.4$ & $1.8 \pm 0.4$ & $1.4 \pm 0.3$ & $1.6 \pm 0.1$ & $1.8 \pm 0.7$ & $1.8 \pm 0.2$ & $2.2 \pm 0.5$ \\
\hline Glucose (mM) & $6.2 \pm 1.5$ & $6.7 \pm 1.6$ & $6.1 \pm 1.0$ & $6.2 \pm 1.6$ & $6.9 \pm 0.9$ & $6.4 \pm 0.8$ & $7.6 \pm 1.7$ & $8.9 \pm 1.6$ \\
\hline Urea $(\mathrm{mM})$ & $21 \pm 3$ & $22 \pm 4$ & $20 \pm 2$ & $20 \pm 3$ & $19 \pm 4$ & $20 \pm 2$ & $20 \pm 3$ & $21 \pm 4$ \\
\hline Plasma creatinine $(\mu \mathrm{M})$ & $36 \pm 6$ & $32 \pm 2$ & $30 \pm 3 *$ & $32 \pm 3$ & $32 \pm 2$ & $30 \pm 2$ & $27 \pm 3$ & $30 \pm 4$ \\
\hline $\begin{array}{l}\text { Twentyfour hour urine } \\
\text { volume (mL/100 g bw) }\end{array}$ & $49 \pm 12$ & $56 \pm 16$ & $56 \pm 20$ & $66 \pm 38$ & $59 \pm 19$ & $40 \pm 20$ & $28 \pm 16$ & $32 \pm 5$ \\
\hline Urine creatinine $(\mu \mathrm{M})$ & $2859 \pm 907$ & $2980 \pm 1248$ & $3108 \pm 2000$ & $2370 \pm 760$ & $2276 \pm 841$ & $3408 \pm 1605$ & $2752 \pm 1045$ & $3129 \pm 387$ \\
\hline Urine $\mathrm{pH}$ & $6.2 \pm 0.6$ & $6.1 \pm 0.2$ & $6.5 \pm 0.4$ & $6.3 \pm 0.5$ & $6.2 \pm 0.2$ & $6.9 \pm 0.6^{*}$ & $6.5 \pm 0.3$ & $7.4 \pm 0.5^{\mathrm{a}}$ \\
\hline $\begin{array}{l}\text { Brain dopamine } \\
\text { (nmol/g brain tissue) }\end{array}$ & $15.2 \pm 2.2$ & $15.2 \pm 1.6$ & $13.6 \pm 4.0$ & $16.0 \pm 3.7$ & $16.1 \pm 1.2$ & $16.7 \pm 1.5$ & $19.2 \pm 1.7$ & $20.2 \pm 0.4$ \\
\hline $\begin{array}{l}\text { Brain noradrenaline } \\
\text { (nmol/g brain tissue) }\end{array}$ & $5.6 \pm 1.4$ & $6.9 \pm 0.7$ & $7.3 \pm 3.6$ & $6.4 \pm 1.6$ & $6.2 \pm 0.8$ & $6.1 \pm 0.6$ & $6.4 \pm 0.7$ & $7.2 \pm 0.8$ \\
\hline $\begin{array}{l}\text { Brain 5-HT } \\
\text { (nmol/g brain tissue) }\end{array}$ & $1.7 \pm 0.2$ & $1.7 \pm 0.1$ & $1.7 \pm 0.5$ & $1.8 \pm 0.2$ & $1.8 \pm 0.2$ & $1.9 \pm 0.1$ & $1.7 \pm 0.1$ & $1.8 \pm 0.02$ \\
\hline
\end{tabular}


ALT: alanine aminotransferase, ALP: alkaline phosphatase. $N$ is 6-8. Data are mean $\pm \mathrm{SD}$. *designates $\mathrm{p}<0.05$ by Dunn's multiple comparisons test (KruskalWallis) vs. Control, adesignates $\mathrm{p}<0.05$ by Mann-Whitney test vs. Male vehicle-BSA .\#\#designates $\mathrm{p}<0.001$ by students t-test vs. Male vehicle-BSA. ${ }^{\# d e s i g n a t e s}$ $\mathrm{p}<0.005$ by students t-test vs. Male vehicle-BSA. 
Table 4. Absolute organ weights of rats treated orally by gavage for 28 days with SeNP or selenite

\begin{tabular}{|c|c|c|c|c|c|c|c|c|}
\hline \multirow[b]{3}{*}{ Dose (mg/kg bw/day) } & \multicolumn{6}{|l|}{ Females } & \multicolumn{2}{|l|}{ Males } \\
\hline & Vehicle-BSA & $\begin{array}{l}\text { SeNP } \\
\text { low-dose }\end{array}$ & $\begin{array}{l}\text { SeNP } \\
\text { mid-dose }\end{array}$ & Vehicle- $\mathrm{H}_{2} \mathrm{O}$ & $\begin{array}{l}\text { Selenite } \\
\text { low-dose }\end{array}$ & $\begin{array}{l}\text { Selenite } \\
\text { mid-dose }\end{array}$ & Vehicle-BSA & $\begin{array}{l}\text { SeNP } \\
\text { high-dose }\end{array}$ \\
\hline & $0(\mathrm{n}=8)$ & $0.05(\mathrm{n}=6)$ & $0.5(n=6)$ & $0(\mathrm{n}=8)$ & $0.05(n=8)$ & $0.5(n=8)$ & $0(n=6)$ & $4(n=4$ at end $)$ \\
\hline Adrenals (g) & $0.06 \pm 0.01$ & $0.06 \pm 0.01$ & $0.06 \pm 0.01$ & $0.06 \pm 0.01$ & $0.06 \pm 0.01$ & $0.06 \pm 0.02$ & $0.06 \pm 0.01$ & $0.05 \pm 0.00$ \\
\hline Brain (g) & $1.75 \pm 0.05$ & $1.68 \pm 0.07$ & $1.70 \pm 0.08$ & $1.73 \pm 0.08$ & $1.73 \pm 0.07$ & $1.67 \pm 0.08$ & $1.96 \pm 0.07$ & $1.85 \pm 0.03$ \\
\hline Heart (g) & $0.64 \pm 0.05$ & $0.62 \pm 0.03$ & $0.60 \pm 0.04$ & $0.61 \pm 0.02$ & $0.64 \pm 0.06$ & $0.64 \pm 0.05$ & $0.92 \pm 0.08$ & $0.90 \pm 0.16$ \\
\hline Kidneys (g) & $1.35 \pm 0.11$ & $1.24 \pm 0.07$ & $1.28 \pm 0.10$ & $1.29 \pm 0.10$ & $1.31 \pm 0.13$ & $1.33 \pm 0.13$ & $1.90 \pm 0.10$ & $1.86 \pm 0.12$ \\
\hline Liver (g) & $5.40 \pm 0.30$ & $4.63 \pm 0.20 *$ & $5.67 \pm 0.75$ & $4.97 \pm 0.44$ & $4.91 \pm 0.48$ & $6.09 \pm 0.50^{\S \S \S}$ & $7.61 \pm 0.59$ & $9.33 \pm 0.88$ \\
\hline Lnd. Mesenteric (g) & $0.18 \pm 0.03$ & $0.18 \pm 0.03$ & $0.16 \pm 0.05$ & $0.21 \pm 0.05$ & $0.20 \pm 0.07$ & $0.21 \pm 0.04$ & $0.32 \pm 0.06$ & $0.27 \pm 0.07$ \\
\hline Ovaries (g) & $0.09 \pm 0.01$ & $0.08 \pm 0.01$ & $0.09 \pm 0.02$ & $0.09 \pm 0.01$ & $0.10 \pm 0.01$ & $0.09 \pm 0.01$ & & \\
\hline Spleen (g) & $0.47 \pm 0.06$ & $0.39 \pm 0.03^{*}$ & $0.44 \pm 0.07$ & $0.43 \pm 0.05$ & $0.44 \pm 0.04$ & $0.48 \pm 0.05$ & $0.64 \pm 0.09$ & $0.66 \pm 0.13$ \\
\hline Testes (g) & & & & & & & $3.27 \pm 0.39$ & $2.63 \pm 0.28^{\dagger}$ \\
\hline Epididymis (g) & & & & & & & $0.75 \pm 0.04$ & $0.57 \pm 0.10^{\dagger \dagger}$ \\
\hline Thymus (g) & $0.47 \pm 0.12$ & $0.39 \pm 0.06$ & $0.40 \pm 0.07$ & $0.44 \pm 0.10$ & $0.45 \pm 0.04$ & $0.37 \pm 0.05$ & $0.48 \pm 0.09$ & $0.34 \pm 0.05$ \\
\hline
\end{tabular}

$N$ is 4-8. One-way ANOVA with Dunnet's post-test was conducted on female SeNP groups and vehicle. Student's t-test was conducted compare male SeNP with vehicle. Data are mean \pm SD. *indicates significance by one-way ANOVA followed by Dunnet’s post-test, vehicle vs. SeNP 0.05 and SeNP $0.5 \mathrm{mg} / \mathrm{kg}$ bw/day in the female group. ${ }^{\S}$ indicates significance by one-way ANOVA followed by Dunnet’s post-test, vehicle vs. selenite 0.05 , and selenite $0.5 \mathrm{mg}$ Se/kg bw/day. ${ }^{\dagger}$ indicates significance by t-test vs. male vehicle. Lnd. is an abbreviation for lymph node. For testes and kidneys the reported weights are combined weights of both the right and left organs. 
Table 5. Relative organ weights of rats treated orally by gavage for 28 days with SeNP or Selenite

\begin{tabular}{|c|c|c|c|c|c|c|c|c|}
\hline \multirow[b]{3}{*}{ Dose (mg/kg bw/day) } & \multicolumn{6}{|l|}{ Females } & \multicolumn{2}{|l|}{ Males } \\
\hline & Vehicle-BSA & $\begin{array}{l}\text { SeNP } \\
\text { low-dose }\end{array}$ & $\begin{array}{l}\text { SeNP } \\
\text { mid-dose }\end{array}$ & Vehicle- $\mathrm{H}_{2} \mathrm{O}$ & $\begin{array}{l}\text { Selenite } \\
\text { low-dose }\end{array}$ & $\begin{array}{l}\text { Selenite } \\
\text { mid-dose }\end{array}$ & Vehicle-BSA & $\begin{array}{l}\text { SeNP } \\
\text { high-dose }\end{array}$ \\
\hline & $0(n=8)$ & $0.05(n=6)$ & $0.5(n=6)$ & $0(\mathrm{n}=8)$ & $0.05(n=8)$ & $0.5(n=8)$ & $0(n=6)$ & $4(n=4$ at end $)$ \\
\hline \multicolumn{9}{|l|}{ (g/100 g bw) } \\
\hline Adrenals & $0.03 \pm 0.01$ & $0.04 \pm 0.01$ & $0.04 \pm 0.00$ & $0.04 \pm 0.01$ & $0.03 \pm 0.00$ & $0.03 \pm 0.01$ & $0.02 \pm 0.00$ & $0.02 \pm 0.00$ \\
\hline Brain & $0.93 \pm 0.05$ & $1.02 \pm 0.07$ & $1.00 \pm 0.10$ & $0.96 \pm 0.05$ & $0.98 \pm 0.05$ & $0.96 \pm 0.06$ & $0.69 \pm 0.05$ & $0.75 \pm 0.04$ \\
\hline Heart & $0.34 \pm 0.04$ & $0.37 \pm 0.02$ & $0.35 \pm 0.02$ & $0.34 \pm 0.02$ & $0.36 \pm 0.03$ & $0.36 \pm 0.03$ & $0.32 \pm 0.02$ & $0.36 \pm 0.07$ \\
\hline Kidney & $0.72 \pm 0.04$ & $0.75 \pm 0.04$ & $0.76 \pm 0.04$ & $0.72 \pm 0.06$ & $0.74 \pm 0.05$ & $0.76 \pm 0.04$ & $0.67 \pm 0.04$ & $0.75 \pm 0.06$ \\
\hline Liver & $2.88 \pm 0.13$ & $2.81 \pm 0.21$ & $3.34 \pm 0.26^{* *}$ & $2.76 \pm 0.21$ & $2.78 \pm 0.25$ & $3.48 \pm 0.22^{\S \S \S}$ & $2.67 \pm 0.11$ & $3.77 \pm 0.21^{\dagger \dagger \dagger}$ \\
\hline Lnd. Mesenteric & $0.10 \pm 0.02$ & $0.11 \pm 0.02$ & $0.10 \pm 0.02$ & $0.11 \pm 0.02$ & $0.12 \pm 0.04$ & $0.12 \pm 0.03$ & $0.11 \pm 0.02$ & $0.11 \pm 0.03$ \\
\hline Ovaries & $0.05 \pm 0.01$ & $0.05 \pm 0.01$ & $0.05 \pm 0.01$ & $0.05 \pm 0.00$ & $0.05 \pm 0.01$ & $0.05 \pm 0.01$ & & \\
\hline Spleen & $0.25 \pm 0.02$ & $0.24 \pm 0.02$ & $0.26 \pm 0.04$ & $0.24 \pm 0.03$ & $0.25 \pm 0.03$ & $0.28 \pm 0.03^{\S}$ & $0.22 \pm 0.03$ & $0.27 \pm 0.05$ \\
\hline Testes & & & & & & & $1.15 \pm 0.10$ & $1.06 \pm 0.04$ \\
\hline Epididymis & & & & & & & $0.26 \pm 0.02$ & $0.23 \pm 0.03^{\dagger}$ \\
\hline Thymus & $0.25 \pm 0.06$ & $0.23 \pm 0.03$ & $0.24 \pm 0.02$ & $0.24 \pm 0.04$ & $0.25 \pm 0.02$ & $0.21 \pm 0.03$ & $0.17 \pm 0.03$ & $0.14 \pm 0.01$ \\
\hline
\end{tabular}

$N$ is 4-8. One-way ANOVA with Dunnet's post-test was conducted on female SeNP groups and vehicle. Student's t-test was conducted compare male SeNP with vehicle. Data are mean \pm SD. *indicates significance by one-way ANOVA followed by Dunnet’s post-test, vehiclevs. SeNP 0.05 and SeNP $0.5 \mathrm{mg} / \mathrm{kg}$ bw/day in the female group. ${ }^{\S}$ indicates significance by one-way ANOVA followed by Dunnet’s post-test, vehicle vs. selenite 0.05 and selenite $0.5 \mathrm{mg}$ Se/kg bw/day. ${ }^{\dagger}$ indicates significance by t-test vs. male vehicle. Lnd. is an abbreviation for lymph node. For testes and kidneys the reported weights are combined weights of both the right and left organs. 